\title{
Public health risks associated with apples and carrots sold in major markets in Osogbo, Southwest Nigeria
}

\author{
M. A. Adeleke ${ }^{1 \star}$, A. O. Hassan ${ }^{2}$, T. T. Ayepola ${ }^{1}$, T. M. Famodimu ${ }^{1}$, W. O. Adebimpe ${ }^{3}$ and \\ G. O. Olatunde ${ }^{1}$ \\ ${ }^{1}$ Public Health Entomology and Parasitology Unit, Department of Biological Sciences, \\ Osun State University, P. M. B 4429, Osogbo, Nigeria. \\ ${ }^{2}$ Microbiology Unit, Ladoke Akintola University Teaching Hospital, Osogbo, Nigeria. \\ ${ }^{3}$ Department of Community Medicine, College of Health Sciences, Osun State University, Osogbo, Nigeria.
}

Accepted 23 August, 2012

\begin{abstract}
This study investigated the public health risks associated with the consumption of carrots and apples sold in major markets in Osogbo metropolis, Osun State Nigeria. Hundred samples of the fruits (49 apples and 51 carrots) were obtained from five randomly selected spots in the four major markets, namely, Igbonna, Oke-fia, Alekuwodo, and Orisumbare in Osogbo metropolis. The samples were screened for microbial and parasitic contaminants using standard procedures. Seven microbial isolates, Pseudomonas aeruginosa, Staphylococcus aeureus, Enterococcus faecalis, Bacillius cereus, Listeri monocytogenes, Citrobacter species, and Candida species; and two parasitic organisms, cysts of Entamoeba coli and ova of Ascaris lumbricoides were isolated from the fruits. The frequency of contaminants and the microbial load were higher in carrots than apples, though the variations were not statistically significant $(P>0.05)$. There were significant variations in the level of parasitic contaminants of the fruits between the markets (Apple, $\mathrm{P}=0.035$; Carrot, $\mathrm{P}=0.007$ ). The results therefore demonstrated that carrots and apples sold in the major markets in Osogbo metropolis are contaminated with microbial pathogens and parasites that are capable of causing food-borne disorders to consumers. The vendors and the residents need to be educated on the public health risks inherent in unwholesome hygienic practices and its attendants effects in causing food-borne illnesses in the study area.
\end{abstract}

Key words: Fruits, carrots, apple, contamination, parasites, microorganisms, Nigeria.

\section{INTRODUCTION}

Fruits constitute the natural sources of vitamins and mineral nutrients to the body. They are used as nutritional remedies for many patients suffering from different ailments such as diabetes, constipations, and stroke (Obeta et al., 2011). Carrot and apple to be specific, have been known to contain antioxidants, vitamin A, vitamin C, fiber, and carotene which help in boosting immunity of the system and protect the cellular anatomical composition of the body (Eni et al., 2010; Whitney-Chavex, 2011). The two fruits also help in boosting insulin in the body, therefore targeted as part of nutritional composition of diabetic patients (Whitney-Chavex, 2011). However, despite the health benefits associated with these two

\footnotetext{
${ }^{*}$ Corresponding author. E-mail: healthbayom@yahoo.com.
}

fruits, the risks of contamination with parasitic and pathogenic microorganisms cannot be under evaluated. These fruits are irrigated with water that may probably be contaminated with pathogenic organisms. Parasitological and microbial studies on the soil and rivers in Nigeria have shown heavy contamination with many pathogenic organisms (Sam-Wobo and Mafiana, 2005; Olayemi, 1994; Kanu and Achi, 2011; Agbabiaka and Oyeyiola, 2012). The pre-harvesting and harvesting processes of the two fruits make them to be prone to parasitic and microbial contaminants in the soil and water (Eni et al., 2010).

While it is acknowledged that some authors have made attempts to document the microbial and parasitic qualities of fruits and vegetables sold in different parts of Nigeria (Chukwu et al., 2010; Eni et al., 2010; Alli et al., 2011; Obeta et al., 2011; Oranusi and Braide, 2012), a review 
of their results showed significant variations in the prevalence and the species composition of the pathogenic organisms isolated from these food items. These variations, which could be traced to differences in environmental pollution, possibly point to the fact that non-uniform epidemiological patterns of the pathogenic organisms associated with the fruits and vegetables should be expected in different parts of Nigeria. This observation, therefore calls for nationwide surveillance to better our understanding on the epidemiological pattern of extrinsic food borne diseases and recommend the appropriate measures to circumvent the risks. Carrot and apples constitute the predominant fruits in Osogbo metropolis and they are available all year round. These carrots are sold by various vendors, and in most cases, are eaten either without being washed or washed with water whose quality is unknown. Only few people take proper care in washing them thoroughly before eating. To the best of our knowledge and available literature search, no previous record exist on the parasitic and microbial contaminants of the fruits sold in Osogbo metropolis, an urban area in Southwestern Nigeria.

The objective of this study was to investigate the parasitic and microbial contaminants associated with apples and carrots sold in major markets in Osogbo metropolis, Southwestern Nigeria with the underline aims of understanding the epidemiology of food-borne diseases and recommend appropriate measures in eliminating the risks towards attaining healthy living of the people in the study area.

\section{MATERIALS AND METHODS}

\section{Study area}

This study was conducted in Osogbo metropolis which lies on latitude $7^{\circ} 49^{\prime} \mathrm{N}$ and a longitude $4^{\circ} 37^{\prime} \mathrm{E}$ in Southwestern Nigeria. Osogbo is the state capital of Osun State and the city is occupied by both elites and indigenous residents.

\section{Samples collection}

Both carrots and apples are not grown in the study area. The fruits are normally transported in cartons by the vendors far away from Southwestern Nigeria. A total of 100 samples of the two fruits were obtained from five randomly selected spots in the four major markets, namely Igbonna, Oke-fia, Alekuwodo, and Orisumbare in Osogbo metropolis. Five vendors were visited per market to obtain five samples of the fruits (a minimum of two of each fruit per vendor). The samples were collected into sterile containers and transported to the laboratory for analysis.

\section{Isolation of microorganisms}

The samples were washed with normal saline in $100 \mathrm{ml}$ round bottom clean plastic containers. $0.01 \mathrm{ml}$ of the sample was then taken from each container and cultured on MacConkey, Sabouraud's dextrose agar, and chocolate agar plate and were incubated overnight at $37^{\circ} \mathrm{C}$.

\section{Bacteriological analysis of the samples}

The colonies were identified by standard bacteriological procedures as described by Cowan and Steel (1975). Gram's staining was performed to determine if the organism is gram negative or gram positive. A smear of the test organism was made on a clean slide, dried and covered with crystal violet for 30 to $60 \mathrm{~s}$. It was washed off with clean water and was covered with Lugol's iodine for 30 to $60 \mathrm{~s}$ and later washed off with clean water. The slide was decolorized with acetone-alcohol, and was washed immediately with clean water and was covered again with neutral red stain for 2 min, and was washed off with clean water. The back of the slide was wiped clean and placed in a draining rack for the smear to air dry. The slide was examined microscopically with the oil immersion lens after the application of the oil on the slide. Gram-positive bacteria gave a dark purple colour while Gram-negatives give a red colour.

\section{Biochemical tests}

Series of biochemical tests such as catalase, citrate, coagulase, oxidase, and urease were performed on the bacteria isolates in accordance with procedures highlighted by Baron and Finegold (1990) and Chaichanawongsaroj et al. (2004).

\section{Mycological analysis of the samples}

The fungi isolates were identified by microscopic examination of the actively growing mould using morphological characters such as the absence or presence rhizoid, colour, and micro-morphology of their sporulating structures and conida (Evans and Richrdson, 1989; Onions et al., 1981).

\section{Microbial load determination}

Enumeration of microorganisms present in each sample was done by 10 -fold serial dilutions using the pour plate method. Counts were made on plates showing discrete colonies. The overall load of the organisms was counted and expressed as colony forming unit (c.f.u) together.

\section{Parasitological analysis of the samples}

The samples's aliquots in $100 \mathrm{ml}$ round bottom clean plastic container were allowed to stand on the bench for few hours to allow proper sedimentation in accordance with Alli et al. (2011). The supernatant was discarded with a Pasteur pipette leaving about 15 $\mathrm{ml}$ at the bottom. $10 \mathrm{ml}$ of the deposit was transferred into a centrifuge tube and was spun for $5 \mathrm{~min}$ at $3,000 \mathrm{rpm}$. The supernatant was decanted while the deposit was re-suspended with $10 \%$ formal saline and was centrifuged. The supernatant was decanted and the deposit was then transferred into a clean glass slide. A drop of iodine was added as stain and covered with a cover slip. The slides were examined under $\times 400$ microscope for parasite ova and cysts as previously described by Alli et al. (2011).

\section{Statistical analysis}

The student t-test and Chi-square were used to determine the significant difference in the prevalence of the organisms and the microbial load between the markets using Statistical Package for Social Sciences (SPSS) version 16.0. 
Table 1. The frequency of contamination of fruits by microbial agents.

\begin{tabular}{lcccc}
\hline Market & No. of apple screened & No. of carrots screened & No. of apple contaminated & No. of carrot contaminated \\
\hline Igbona & 12 & 13 & 6 & 9 \\
Alekuwodo & 13 & 12 & 3 & 6 \\
Okefia & 12 & 13 & 0 & 5 \\
Orisumbare & 12 & 13 & 3 & 6 \\
Total & 49 & 51 & $12(24.0 \%)$ & $26(50.9 \%)$ \\
\hline
\end{tabular}

Table 2. Microbial load and diversity of the microorganisms isolated from the fruits.

\begin{tabular}{lccccc}
\hline Micro-organism & $\begin{array}{c}\text { No. of fruits } \\
\text { screened }\end{array}$ & $\begin{array}{c}\text { No. of isolate } \\
\text { for carrot }\end{array}$ & $\begin{array}{c}\text { Mean load } \\
\text { (CFU) }\end{array}$ & $\begin{array}{c}\text { No. of isolate } \\
\text { for apple }\end{array}$ & $\begin{array}{c}\text { Mean load } \\
\text { (CFU) }\end{array}$ \\
\hline B. cereus & 100 & 2 & $1.0 \times 10^{4}$ & 6 & $1.0 \times 10^{3}$ \\
S. aereus & 100 & 2 & $1.0 \times 10^{2}$ & 1 & $1.0 \times 10^{1}$ \\
E. faecalis & 100 & 1 & $1.0 \times 10^{1}$ & Not found & Nil \\
L. monocytogenes & 100 & 1 & $1.0 \times 10^{4}$ & Not found & Nil \\
P. aeruginosa & 100 & Not found & Nil & 1 & $1.0 \times 10^{3}$ \\
C. species & 100 & 3 & $1.0 \times 10^{3}$ & Not found & Nil \\
C. species & 100 & 3 & $1.0 \times 10^{4}$ & Not found & Nil \\
\hline
\end{tabular}

Table 3. The frequency of contamination of the fruits by the parasites.

\begin{tabular}{lcccc}
\hline Market & $\begin{array}{c}\text { No. of fruits } \\
\text { screened for apple }\end{array}$ & $\begin{array}{c}\text { No. of fruits } \\
\text { screened for carrot }\end{array}$ & $\begin{array}{c}\text { No. of apple } \\
\text { contaminated }\end{array}$ & $\begin{array}{c}\text { No. of carrot } \\
\text { contaminated }\end{array}$ \\
\hline Igbona & 12 & 13 & 3 & 4 \\
Alekuwodo & 13 & 12 & 1 & 4 \\
Okefia & 12 & 13 & 1 & 2 \\
Orisumbare & 12 & 13 & 2 & 3 \\
Total & 49 & 51 & $7(14.3 \%)$ & $25(\%)$ \\
\hline
\end{tabular}

\section{RESULTS}

\section{Microbial studies}

The results of the bacteriological and mycological identifications revealed seven isolates namely, Pseudomonas aeruginosa, Staphylococcus aeureus, Enterococcus faecalis, Bacillius cereus, Listeri monocytogenes, Citrobacter sp. and Candida sp. were isolated from the fruits. However, more carrots (50.9\%) were contaminated than apples (24\%) (Table 1), the result of pair wise statistical analysis showed that there was no significant difference in the frequency of contamination of the two fruits $(P=0.06 ; P>0.05)$. While the frequency of contamination of carrots varied significantly between the markets as revealed by $t$-test $(P=0.005 ; P<0.05)$, there was no significant difference in the contamination of apples between the markets $(P=0.092 ; P>0.05)$. All the isolates encountered were found as contaminants of carrots with the exception of $P$. aeruginosa, while three out of the seven isolates were found as contaminants of apples with $B$. cereus constituting the most frequent contaminant of apple (Table 2). The microbial load of the isolates ranged between $1.0 \times 10^{1}$ and $1.0 \times 10^{4}$ in carrots and $1.0 \times 10^{1}$ to $1.0 \times 10^{3}$ in apples.

\section{Parasitological studies}

The parasitological analysis of the samples showed that more carrots $(25 \%)$ were also contaminated with parasites than apples (14.3\%) (Table 3), but the difference in the level of contamination was not significant $(P=0.058 ; P>0.05)$. There were significant variation in the level of contamination of the fruits between the markets (Apple, $\mathrm{P}=0.035$; Carrot, $\mathrm{P}=0.007$ ). Only the cysts of Entamoeba coli (2 cysts per fruit) and ova of Ascaris lumbricoides (1 ova per fruit) were found on the fruits. 


\section{DISCUSSION}

The observations from the present study revealed the microbial and parasitic contamination of the apples and carrots available for consumption in Osogbo Metropolis. The contamination, which could be a reflection of poor sanitary conditions of the environment where the fruits were cultivated or handled by the vendors. Studies have shown that most of the soil and rivers in Nigeria are heavily contaminated with pathogens (Sam-Wobo and Mafiana, 2005; Olayemi, 1994; Kanu and Achi, 2011; Agbabiaka and Oyeyiola, 2012). These fruits would have been contaminated from the field and the pathogens were subsequently transported to the store. The isolation of faecal microbial isolates and the recovery of the cysts of $E$. coli and ova of $A$. lumbricoides attest to the faecal contamination of the fruits either by water used for the irrigation or the soil of the cultivating area. On the other hand, poor sanitary conditions have also been reported among Nigerian after defecation (Sam-Wobo and Mafiana, 2005) and the tendency of contamination of the fruit samples by the vendors could not be ignored. This may also be the reason to justify the variation in the level of contamination of the fruits between the markets used for the study or the differences in the source of cultivation of the fruits. The public health implications of these findings are enormous. Prevalence of diarrhoeal diseases may be on the increase among subjects who consumed these fruits without proper washing. In Nigeria, carrots are important component of salad and similar foods, which are eaten raw or half cooked. Incidence of food poisoning cannot be ruled out in societies with poor personal hygiene and where food vendors are not routinely screened or registered.

Though, the frequency and microbial load of the pathogens were low when compared with similar studies in other parts of Nigeria (Eni et al., 2010; Alli et al., 2011; Kanu and Achi, 2011; Oranusi and Braide, 2012), the isolation of these organisms, no matter the level, raises considerable public health concern when considering their pathogenicity. Most of the isolates including the parasites $(A$. lumbricoides and $E$. colli) found on the fruits have been reported to cause gastrointestinal disorders and chronic diarrhorea (Alli et al., 2011; Oranusi and Braide, 2012). Therefore, consumption of these fruits without proper wash signifies the risks of gastrointestinal disorders among the residents.

The higher risk could be found among children consuming improperly washed fruits, including infestation by worms observed in this study. Worms infestation is a common cause of failure to thrive, growth retardation, and impaired cognitive functions among children (SamWobo and Mafiana, 2005). It is thus important that these fruits pass the food hygiene test right from harvesting to consumption, while all stakeholders obeys existing public health laws towards morbidity reduction most especially among children consuming these fruits from time to time. The higher contamination of the carrots with parasites and microorganisms poses more public health challenge, in that the fruit is cheap when compared with other fruits and it is the most hawked fruit in Osogbo metropolis. Carrot is consumed by both economically low and affluent classes. While the later group may take precautionary measures to wash the fruit thoroughly before eating (possibly due to their educational status), the former group most of the time, eat the fruit as consumed from the vendors (Eni et al., 2010).

\section{Conclusion}

The results of this study have demonstrated that carrots and apples sold in the major markets in Osogbo metropolis are contaminated with pathogens and parasites that are capable of causing food-borne disorders to the consumers. There is need for proper washing of the fruits with clean source of water before consumption. The vendors and the residents also need to be educated on the public health risks inherent in unwholesome hygienic practices and its attendants effects in causing food borne illness in the study area.

\section{ACKNOWLEDGEMENTS}

The authors acknowledge the support of the Management and staff of Group Diagnostica, Oke-fia Osogbo to the study.

\section{REFERENCES}

Agbabiaka TO, Oyeyiola G (2012). Microbial and physic-chemical assessment of Foma river, Itanmo, Ilorin Nigeria: An important source of domestic water in Ilorin metropolis. Int. J. Plant Anim. Environ. Sci. 1:209-216.

Alli JA, Abolade GO, Kolade AF, Salako AO, Mgbakor CJ, Ogundele MT, Oyewo AJ, Agboola MO (2011). Prevalence of intestinal parasites on fruits available in lbadan Markets, Oyo State. Acta Parasitological Globalis 2(1):6-10

Cowan ST, Steel JL (1975). In: Manual for the identification of medical Bacteria, 2nd Ed. Cambridge University Press 1975. pp. 45-114.

Baron EJ, Finegold SM (1990). Bailey \& Scott's diagnostic microbiology, VIII edn. St. Louis: Mosby Co. pp. 323-861.

Chaichanawongsaroj N, Vanichayatanarak K, Pipatkullachat T, Polrojpanya M, Somkiatcharoen S (2004). Isolation of Gram-negative bacteria from cockroaches trapped from urban environment. Southeast Asian J. Trop. Med. Public Health 35:681-684.

Chukwu CO, Chukwu ID, Onyimba IA, Umeh EG, Olarubofin F, Olabode AO (2010). Microbiological quality of pre-cut fruits on sale in retail outlets in Nigeria. Afr. J. Agric. Res. 5(17):2272-2275.

Eni AO, Oluwawemitan IA, Solomon US (2010). Microbial quality of fruits and vegetables sold in Sango Ota, Nigeria. Afr. J. Food Sci. 4(5):291-296.

Evans EGV, Richrdson MD(1989). Medical mycology: a practical approach. Oxford: Oxford University Press 1989, pp154.

Kanu I, Achi OK (2011). Industrial effluents and the impact on water quality of receiving rivers in Nigeria. J. Appl. Technol. Environ. Sanita. 3:75-86

Obeta SE, Nwakonobi TU, Adikwu OA (2011). Microbial effect of selected stored fruits and vegetables under ambient conditions in Markudi, Benue State, Nigeria. Res. J. Appl. Sci. Engine. Technol. 
3(5):393-398

Olayemi AB (1994). Bacteriological water assessment of an urban river in Nigeria. Int. J. Environ. Health Res. 4:165-164.

Onions AHS, Allsopp A, Eggins HOW (1981). Smiths Introduction to Industrial Mycology, Edward Arnold, London. p. 389

Oranusi US, Braide W (2012). A study of microbial safety of ready-t-eat foods vended on highways, Onitsha-Owerri, Southeast Nigeria. Int. Res. J. Microbiol. 3(2):66-71
Sam-Wobo SO, Mafiana CF (2005). The effects of surface soil physiochemical properties on the prevalence of helminths in Ogun State, Nigeria. Univers. Zambia J. Sci. Technol. 9(2):13-20.

Whitney-Chanex E (2011). The nutritional value of juices, carrots, beets, apple and celery. Food and drink nutrition. www.livinstrong.com 